\title{
COLAGENS DA HETEROGENEIDADE CONTEMPORÂNEA
}

\author{
Andréa Figueiredo Leão Grants* \\ Bianca Rosina Mattia** \\ Izabele Cristini da Silva*** \\ Jair Zandoná ${ }^{* * * *}$ \\ Marina Siqueira Drey ${ }^{* * * *}$ \\ Stélio Furlan ${ }^{* * * * * *}$ \\ Universidade Federal de Santa Catarina
}

Neste primeiro número do $21^{\circ}$ volume da Revista Anuário de Literatura, mais uma vez, o leitor irá se deparar com um profícuo e heterogêneo encontro de estudos. Reunidos, certamente, em virtude da nossa missão primeira, a difusão do conhecimento novo e inovador na área de Literatura, Teoria e Crítica Literária. Assim, temos a satisfação de oferecer para apreciação uma produtiva compilação, diversa não somente na temática, mas também na fundamentação teórica que sustenta os trabalhos aqui apresentados, bem como na localização geográfica dos autores que, de norte a sul do país, compõem esse mosaico literário.

O primeiro ladrilho ${ }^{1}$ dessa imagem é de Raquel Wandelli Loth, que traz à tona o narrador-coruja, em Coruja, lobisomem, vaga-lume: o traço animal do narrador, a fim de

\footnotetext{
(c) (P)

Esta obra está licenciada sob uma Creative Commons - Atribuição 4.0

* Doutoranda e Mestra em Literatura pela UFSC. Bibliotecária do Sistema de Bibliotecas da UFSC. Coordenou o Portal de Periódicos UFSC (2009/jun.2014). Integra a Comissão Editorial da Anuário de Literatura.

** Mestranda do Programa de Pós-Graduação em Literatura da UFSC e integra a Comissão Editorial da Anuário de Literatura.

*** Mestranda do Programa de Pós-Graduação em Literatura da UFSC e integra a Comissão Editorial da Anuário de Literatura.

**** Doutor em Literatura pela UFSC, integra a Comissão Editorial da Anuário de Literatura.

***** Mestranda do Programa de Pós-Graduação em Literatura da UFSC e integra a Comissão Editorial da Anuário de Literatura.

****** Doutor e Mestre pela Universidade Federal de Santa Catarina. Atualmente é Professor Associado junto ao DLLV/UFSC. Atual Editor da Revista da ANPOLL e Editor da revista Anuário de Literatura.

1 A imagem do "mosaico literário" intenciona o diálogo com a capa deste volume da Anuário, uma referência e homenagem aos 55 anos da UFSC a partir do recorte da obra Mosaicos (1995-1997), de Rodrigo de Haro, que reveste as paredes da reitoria da instituição.
}

Anu. Lit., Florianópolis, v. 21, n. 1, p. 7-10, 2016. ISSNe 2175-7917 
explorar a potência não-humana do narrador. Assim, ao olhar, refletir e escrever sobre o inumano, registra um pensamento em crise, aquele cuja origem e fim não são mais regidos pelo homem. Nesse contexto, a autora se propõe a pensar uma rede de narradores de distintas épocas com a intenção de identificar a permanência da animalidade nessas escritas.

Já Eduardo Marks de Marques e Raíssa Cardoso Amaral, em O percurso doloroso entre a prática e a teoria: reflexões sobre a personagem Urania em "A festa do bode", de Mario Vargas Llosa, trabalham com o entrelaçamento de memória e trauma na narrativa da personagem Urania. A intenção é a de discutir as marcas deixadas pela ditadura da Era Trujillo, na República Dominicana, nessa personagem. Com isso, os autores exploram a relação e os desdobramentos entre a vivência histórica e o conhecimento histórico, o que denominam de o "percurso entre e teoria prática", com a intenção de demonstrarem como se deu a reconstrução da identidade dominicana em Urania.

Por sua vez, Anderson de Oliveira Lima, com Gregório de Matos, nosso primeiro antropófago, argumenta em favor da hipótese de que Gregório de Matos foi o primeiro antropófago do Brasil. Para isso, o autor situa o leitor a respeito da polêmica em torno da obra de Gregório de Matos e, posteriormente, trabalha com o pressuposto de que os poemas desse autor já apresentavam características próprias do movimento antropofágico, concebido por Oswald de Andrade na década de 1920.

Com Imagem-palavra: a iconicidade da escrita em "Relato de um certo oriente", de Miltom Hatoum, de Daiane Carneiro Pimentel, retornamos simbolicamente ao nascedouro icônico da escrita. Isso porque a autora procura demonstrar que o romance supracitado traz uma aproximação entre as formas verbais e visuais a partir da "referência ao alfabeto árabe", da "leitura da borra de café", das "formas expressivas de Soraya Ângela e ao cometa escrito/desenhado por Dorner.".

Em Impressões russas da modernidade: Dostoiévski em viagem pela Europa, Paulo Mendonça analisa Notas de inverno sobre impressões de verão, literatura de viagem, de fundo memorialista, que Dostoiévski redigiu quando viajava pela Europa em 1862. Para essa reflexão, Mendonça aborda a origem do vocábulo "modernidade" para, seguidamente, partir para o texto de Dostoiévski com intuito de destacar a criticidade com que o autor russo se propunha a falar sobre as transformações da Europa ao longo da segunda metade do século XIX.

Na sequência, André Rocha Leite Haudenschild, em A experiência revisitada: as artimanhas naturais da narrativa rosiana, convida-nos a pensar a prosa de Guimarães Rosa 
à luz das teorias benjaminianas a respeito do narrador e das transformações da experiência. Com isso, o autor procura compreender como a narrativa de Rosa "transita com autoridade da Erfahrung à Erlebnis" de Walter Benjamim, tensionando a experiência entre a o mundo do sertão e o da metrópole com o ir e vir entre a oralidade sertaneja e o romance de formação.

Com o artigo Wallace Stevens: o hermetismo como leitura do real, de Maria Luísa Fumaneri, somos instigados a conjecturar acerca da poesia moderna. Pois, para a autora, o paralelo entre a obra de Stéphane Mallarmé e Wallace Stevens é capaz de elucidar determinados pontos que dificultaram a interpretação da poesia moderna no curso da história, como "as ligações entre linguagem e realidade e o papel da poesia no conhecimento.".

Já Juan Manuel Terenzi, em Desastre, destruição, criação: do nada às cinzas, apresenta uma discussão "acerca do nada, do fogo, das cinzas e do poder de criação que deles deriva." Para isso, o autor dialoga com alguns conceitos tecidos por Martin Heidegger abordando, também, a leitura elaborada por Jacques Derrida a respeito do conceito de Geist na obra heideggeriana. Assim, tece uma reflexão que parte dos conceitos analisados até chegar ao ato da criação em si.

A leitura de La censura literária: desarrollo conceptual y teórico, los efectos de su acción y su funcionamento, de autoria de Gabriela de Lima Grecco, faz-nos olhar o fenômeno da censura em uma perspectiva teórica e histórica. Nessa conjuntura, a autora se coloca a refletir a partir dos postulados de Pierre Bourdieu e de Michel Foucault com intuito de discutir os sistemas repressivos que regulamentam e decidem a dinâmica de constituição dos sujeitos a ele subordinados.

Ao nos encontrarmos com "O desenho é uma pronúncia": Paula Rego e Agustina Bessa-Luís, de Mariana Andrade da Cruz, somos convidados a pensar o fazer artístico a partir da análise de As meninas, biografia de Paula Rego, cuja assinatura é de Bessa-Luís. Segundo a autora do artigo, Bessa-Luís elabora na biografia de Rego "inúmeras reflexões de ordem metalinguística, bem como acerca das relações entre texto e tela" a partir de aproximações com a sua vida, de forma que o livro passa a propor um fértil diálogo interartes.

Com Ricardo Gessner, n’Os mistérios de Paulo Leminski, temos a oportunidade de ver a poesia leminskiana em um recorte temático. No caso específico, a temática do mistério é estudada por meio da análise de dois poemas do poeta curitibano, "rio do mistério", e "Suprassumo da Quintessência”. Para isso, como norte teórico, o autor utiliza os ensaios do próprio poeta a fim de identificar o que este pensou e desenvolveu no tocante ao assunto em questão. 
A negra que não está na capa de revista: debates sobre raça e gênero, de Gabrielle Vivian Bittelbrun, discute a invisibilização das mulheres negas em capas de revistas femininas. Conforme a autora, ao publicar o mesmo estereótipo de beleza, majoritariamente representado por mulheres brancas, o mercado editorial brasileiro corrobora para o fortalecimento da invisibilidade de outras raças, no caso, da negra. Nesse contexto, Gabrielle Bittelbrun discorre sobre um processo histórico que remete àquilo que identificou como "ideologia de branqueamento".

Em vias de finalização, observamos que a presente edição ainda conta com três resenhas. A primeira, Por el derecho a la palabra, de Amaral Palevi Gómez Arévalo, aborda o livro Indígena, cuerpo y sexualidad en la literatura salvadoreña (2012), de autoria de Rafael Lara-Martínez. A segunda, Pôncio Pilatos: o simulacro, de Égide Guareschi, propõese a discorrer a respeito de Pilatos e Jesus, livro publicado por Giorgio Agambem em 2013. A terceira e derradeira, Últimas faces do poeta: prosa e poesia em Cruz e Sousa em "Últimos inéditos", de Gustavo Tanus, avalia a compilação Últimos inéditos: prosa \& poesia, de Uelinton Farias Alves, de 2013.

Para concluir essa imagem literária, apresentamos ao leitor Fluxo editorial: uma análise quantitativa da Revista Anuário de Literatura (2012-2014), um artigo-memória redigido por três de nossos editores, Andréa Figueiredo Leão Grants, Bianca Rosina Mattia e Stélio Furlan. Nele, os autores procuram apresentar a investigação depreendida acerca do processo editorial da Anuário entre os anos de 2012 e 2014.

Agradecemos@s pareceristas desta edição pelas acuradas avaliações. Aos leitores, por fim, desejamos uma agradável leitura dessa imagem literária que aqui se construiu. Com os melhores cumprimentos,

a Comissão Editorial.

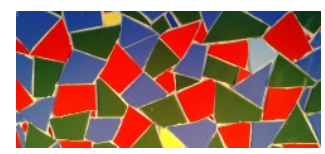

